\title{
A Case of Huge Fibroma in the Palate
}

\author{
Sayaka Yoshiba1*, Koki Takamatsu2 ${ }^{2}$, Shinsuke Nakamura ${ }^{2}$, \\ Junichiro Chikuda², Naoko Kawachi' ${ }^{3}$, Tatsuo Shirota ${ }^{2}$ \\ ${ }^{1}$ Department of Dental and Oral Surgery, Showa University Northern Yokohama Hospital, Tokyo, Japan \\ ${ }^{2}$ Department of Oral and Maxillofacial Surgery, Showa University School of Dentistry, Tokyo, Japan \\ ${ }^{3}$ Department of Dental and Oral Surgery, Health Park Clinic, Gunma, Japan \\ Email: *yoshiba@dent.showa-u.ac.jp
}

How to cite this paper: Yoshiba, S., Takamatsu, K., Nakamura, S., Chikuda, J., Kawachi, N. and Shirota, T. (2018) A Case of Huge Fibroma in the Palate. Open Journal of Clinical Diagnostics, 8, 52-59. https://doi.org/10.4236/ojcd.2018.84006

Received: November 1, 2018 Accepted: December 22, 2018 Published: December 25, 2018

Copyright $\odot 2018$ by authors and Scientific Research Publishing Inc. This work is licensed under the Creative Commons Attribution International License (CC BY 4.0).

http://creativecommons.org/licenses/by/4.0/

\begin{abstract}
Fibroma-like lesions occur with relatively high frequency in oral soft tissues, but represent reactive proliferation against chronic irritation. True fibromas are rare. Tumor size is often seen to range from the mass of a red bean to a soybean. We encountered a case of huge fibroma in the palate with a long history of more than 30 years. The patient was a 60 -year-old man who became aware of a tumor in the right palate about 30 years earlier. The mass had tended to increase in size in recent years, and was introduced to our department for the first visit. As an intraoral finding, a pedicled mass measuring $29 \times 27 \mathrm{~mm}$ was found in the right palate. We also considered the possibility of verrucous carcinoma, and performed biopsy, obtaining a diagnosis of fibroma. Right palatectomy was performed under general anesthesia in October 2016. We performed immunohistochemical examination of the surgical specimen, obtaining a definitive diagnosis of fibroma. As of 1 year postoperatively, no recurrence has been identified and the course has been good.
\end{abstract}

\section{Keywords}

Huge Fibroma, Immunohistological Examination

\section{Introduction}

Fibroma is a benign tumor in which fibroblasts proliferate to form neoplasia, resulting in an increase in collagen fibers. Many of the fibroma-like lesions seen in the oral mucosa represent reparative or reactive hyperplasia of fibrous tissue against chronic irritation, and true neoplastic lesions are considered rare [1] [2]. The size of the tumor often ranges from the mass of a red bean to that of a soybean. It often occurs in the tongue or buccal mucosa in the oral cavity, because it is susceptible to bite and stimulation. In this case, we encountered a case of 
extremely huge fibroma occurring in the palate and developing over more than 30 years, and we report this case with reference to the literature.

\section{Case report}

A 60-year-old man was referred to our department complaining of speech disturbance due to a maxillary mass. His medical history was hypertension and he was receiving hypotensive agents. His family history was unremarkable. The patient became aware of a mass on the right upper jaw about 30 years earlier, but did not seek medical attention because the mass was not associated with any problematic symptoms. About a half a year before this presentation, the patient experienced an increase in tumor mass, and introduced to our department for the first visit.

Extraoral examination showed no abnormality (Figure 1). Intraoral findings exhibited a pedicled mass measuring $29 \mathrm{~mm} \times 27 \mathrm{~mm}$ in the right palate, with a granular surface and no easy bleeding (Figure 2). No abnormal findings such as bone destruction were observed on panoramic radiography. On Computed Tomography, no bone resorption or destruction was seen in the right maxilla at the

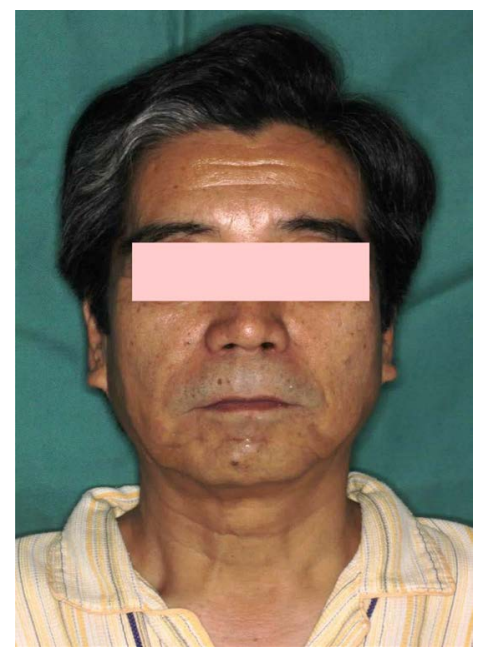

Figure 1. Extraoral findings. Physique and nutritional status are good, and we confirmed a lack of abnormalities from extraoral examination.

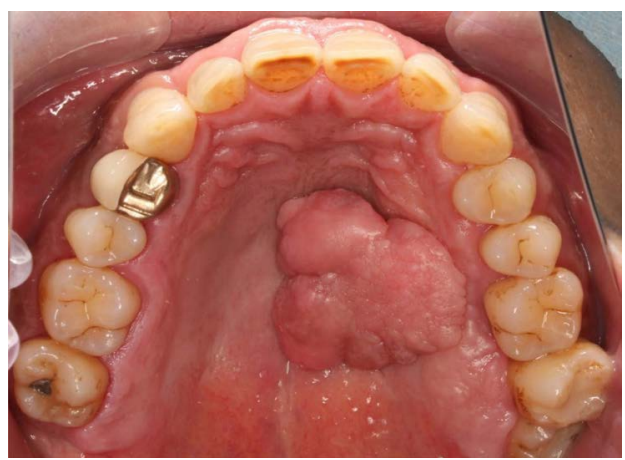

Figure 2. Intraoral findings. A pedunculated mass measuring $30 \mathrm{~mm} \times 27 \mathrm{~mm}$ is recognized in the right palate. 
tumor location site (Figure 3). We also considered the possibility of verrucous carcinoma and performed biopsy that revealed fibroma. We considered the possibility of a malignant component, and right-side maxillary tumor excision was performed under general anesthesia in October 2016. Given the possibility of malignant tumor, the incision line was designed by providing a safety zone of about $5 \mathrm{~mm}$ from the base of the mass lesion. The tumor was excised as a mass including the periosteum. Bone in the surface layer of the removed mass was further ablated using a bone cutting tool. The excised mass was $30 \mathrm{~mm} \times 27 \mathrm{~mm}$ $\times 12 \mathrm{~mm}$, and weighed $31 \mathrm{~g}$. The surface of the mass was uneven, with normal mucosal coloration and elastic hard consistency. The wound surface was covered with collagen artificial skin (graft for Terdermis dermal defects; Olympus Terumo, Tokyo) and fixed to the surrounding gingiva. To protect the wound, ointment gauze was interposed and a hemostatic splint was worn (Figure 4). The hemostatic splint was removed 1 week postoperatively. Pathological examination of the excised material showed augmentation of fibrous connective tissue mediated by small blood vessels under the epithelium. No heteromorphism was found in the stratified squamous epithelium of the surface layer (Figure 5). Subepithelial spindle-shaped cells were negative for S100 protein, CD34, Bcl-2, and Ki-67, and positive for vimentin (Figure 6). Based on these results, a definitive diagnosis of right palate fibroma was obtained. Currently, 12 months postoperatively, no recurrence is seen at the tumor site and the course is good.

\section{Discussion}

Benign neoplastic lesions due to proliferation of fibrous tissue are often found in oral areas, particularly soft tissues, mainly in the mucous membranes. Most merely represent repairable or reactive growths of fibrous tissue against chronic irritation [1] [2] [3]. Gorlin and Goldman [4] reported the extreme rarity of true fibroma in the oral region. Barker and Lucas [3] reported that true fibroid tumors represented only 2 of 650 cases among fibroma-like lesions (0.012\%).
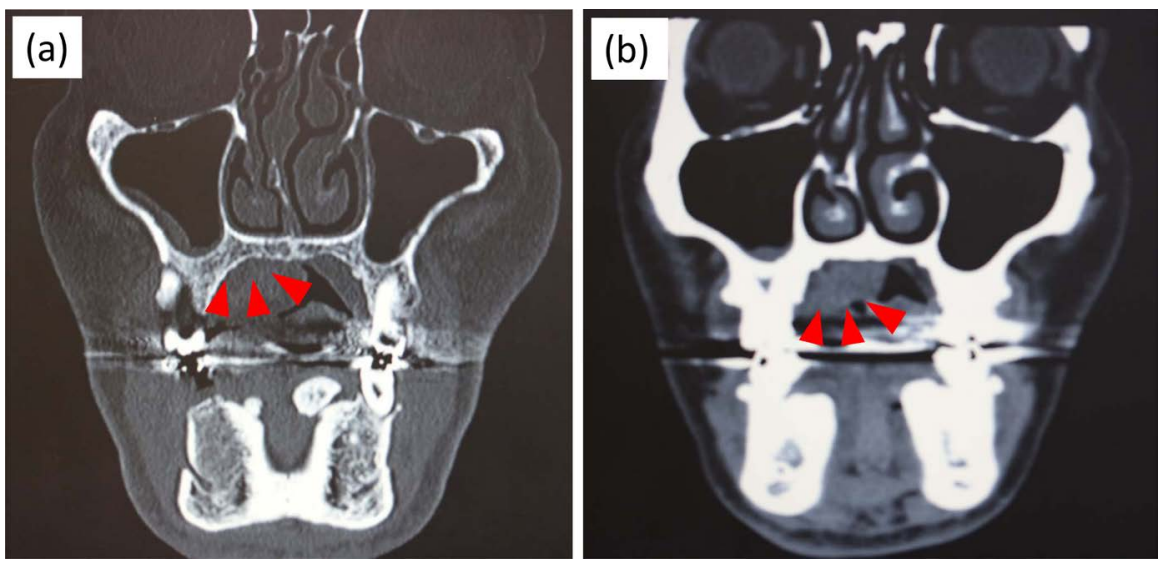

Figure 3. CT findings. (a) Hard tissue mode; (b) Soft tissue mode. No bone destruction is observed in the right mandibular bone of the tumor-equivalent part. No contrast effect is recognized in the right palate tumor. 

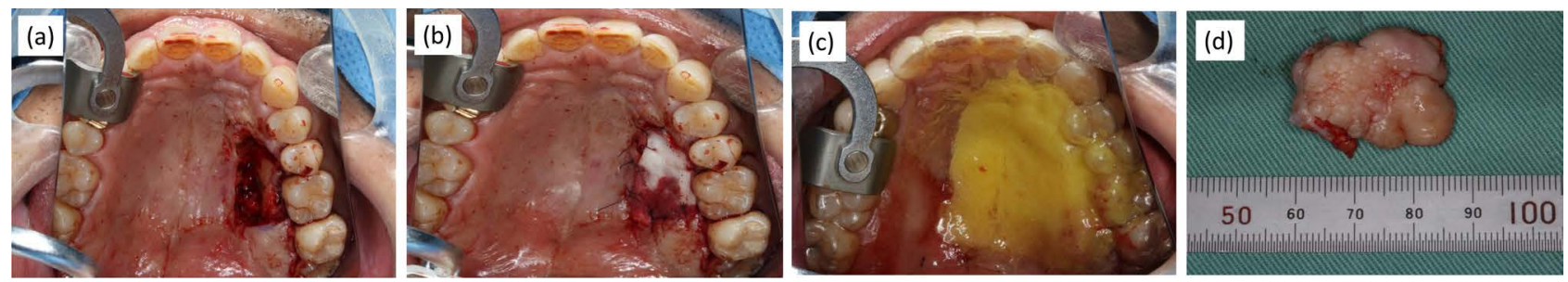

Figure 4. Surgical findings. (a) Surface of the resected tumor; (b) Tumor resected surface is covered with Terdermis; (c) Postoperatively, ointment gauze is interposed and a hemostatic splint is worn; (d) The excised tumor measures $30 \mathrm{~mm} \times 27 \mathrm{~mm} \times 12 \mathrm{~mm}$ in size and weighs $31 \mathrm{~g}$.
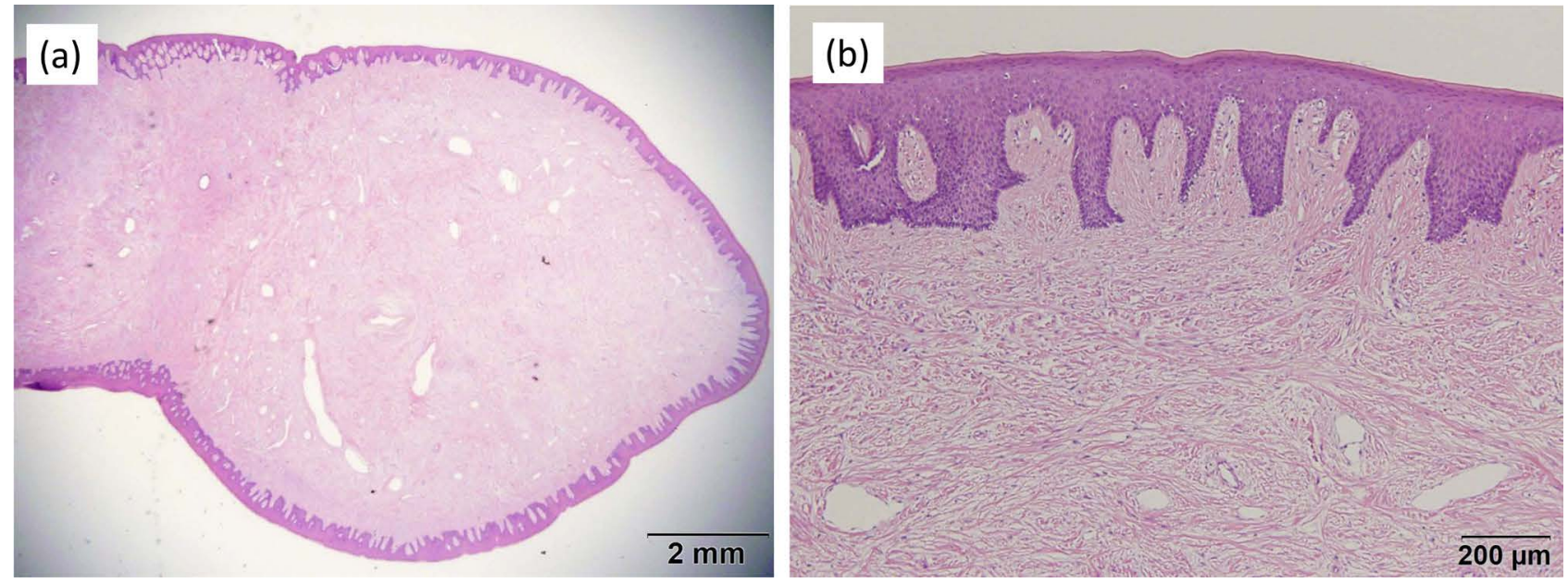

Figure 5. Histopathological image (hematoxylin and eosin staining). (a) $\times 4$; (b) $\times 200$. Increased fibrous connective tissue supplied by small blood vessels under the epithelium, with no heteromorphism in the stratified squamous epithelium covering the surface. The pathological diagnosis is fibroma.

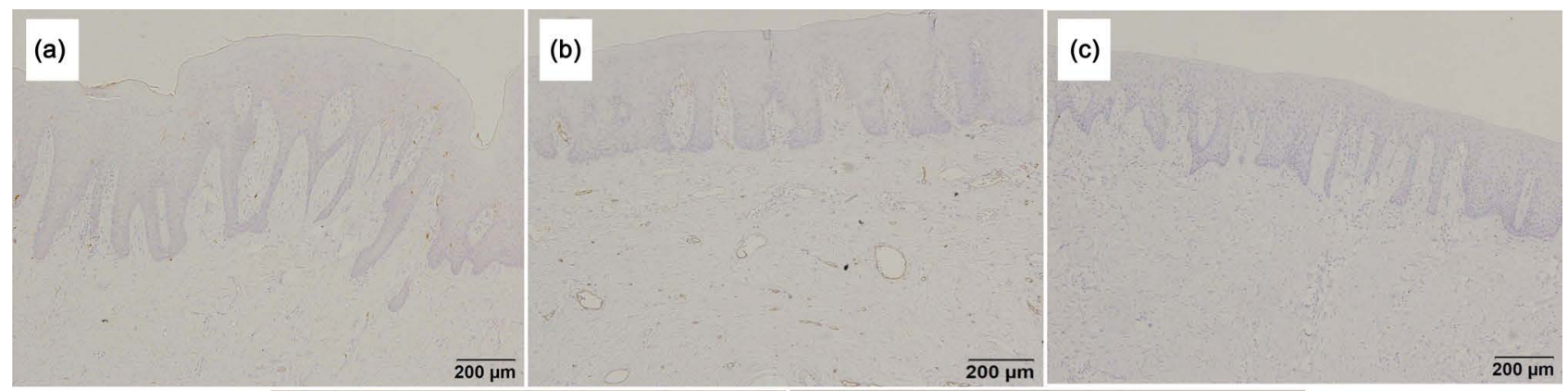

(d)

(e)

Figure 6. Histopathological image (immunostaining). (a) S100, $\times 200$; (b) CD34, $\times 200$; (c) Bcl-2, $\times 200$; (d) Ki-67, $\times 200$; (e) Vimentin, $\times 200$. Subepithelial spindle-shaped cells show negative results for S100 protein, CD34, Bcl-2, and Ki-67, and positive results for vimentin. 
Although irritant fibroma and true fibroma are difficult to distinguish clinically, differentiation can be made on the bases of pathological findings and the presence or absence of clear obvious chronic stimulation [5]. True fibroma is rich in cellular components and the boundary with the surrounding tissue is clear, often showing rigid fibroma. On the other hand, irritant fibroma is rich in collagen fibers showing irregular arrangement, and the boundary with the surrounding tissue is unclear. The epithelial structure covering the surface layer is said to show a tendency to flatten in true fibroma (Table 1 ). In addition, immunohistologically, fibroblasts constituting fibroma have been reported to be identified as $\mathrm{Bcl}-2$ positive. In our case, flattening of the epithelial layer was not recognized as a histopathological image, and the interior of the connective tissue was dominated by collagen fibers showing irregular arrangement. This finding resembled an irritating fibroma as reported by Ishikawa et al. [6]. Bcl-2-positive cells were not detected in subepithelial fibroblasts as a result of immunostaining [7]. This case might thus represent fibroma due to chronic stimulation. Bhasker [5], Bernier [8], and Shafer [9] described the size of fibroma found in the oral cavity as ranging from several millimeters to several centimeters in diameter. In addition, Ishikawa et al. [6] stated that lesions generally ranged from the size of red beans to chicken eggs, with occasional larger masses. In past reports that we were able to identify, 6 cases of fibroma (including our case) were $\geq 3 \mathrm{~cm}$ in size in the oral cavity, and 5 cases occurred in the palate. Huge fibroma thus tends to be seen more frequently in the palate (Table 2). The reason for this is that patients with

Table 1. Differences between neoplastic fibroma and reactive fibroma.

\begin{tabular}{ccc}
\hline & Tumorous fibroma & Reactive fibroma \\
\hline Boundary with surrounding tissue & clarity & ambiguity \\
Density of fibrous tissue & crude (soft fibroma) & dense (hard fibroma) \\
Structure of epithelial layer & flattening & hyperplasia \\
Immunohistological marker & Bcl-2 & horny layer also hypertrophied \\
\end{tabular}

Table 2. Reports on huge fibroma in the oral cavity.

\begin{tabular}{|c|c|c|c|c|c|c|c|}
\hline No. & Reporter & $\begin{array}{l}\text { Report } \\
\text { of year }\end{array}$ & Age/sex & $\begin{array}{c}\text { Period until } \\
\text { removal (year) }\end{array}$ & Position & Size & $\begin{array}{c}\text { Immunohistological } \\
\text { examination }\end{array}$ \\
\hline 1 & Ueda et al. & 1968 & $49 / \mathrm{F}$ & 22 & Median part of paratal & Walnut large & - \\
\hline 2 & Niikuni et al. & 1968 & $48 / \mathrm{M}$ & 6 & Median part of paratal & $50 \times 40 \times 20 \mathrm{~mm}$ & - \\
\hline 3 & Kitagawa et al. & 1980 & $69 / \mathrm{F}$ & 20 & Left palate & $90 \times 65 \times 50 \mathrm{~mm}, 86 \mathrm{~g}$ & - \\
\hline 4 & Sanka et al. & 1987 & $34 / \mathrm{M}$ & $6 \sim 7$ & Median part of paratal & $57 \times 36 \times 20 \mathrm{~mm}, 25 \mathrm{~g}$ & - \\
\hline 5 & Horikoshi et al. & 1987 & $66 / \mathrm{M}$ & 10 & Right upper gum & $50 \times 50 \mathrm{~mm}, 70 \times 50 \mathrm{~mm}, 110 \mathrm{~g}$ & - \\
\hline 6 & Yoshiba et al. & 2014 & $60 / \mathrm{M}$ & 30 & Light palate & $30 \times 27 \times 12 \mathrm{~mm}, 31 \mathrm{~g}$ & $\begin{array}{c}+ \\
\text { (Bcl-2, CD34, S-100, } \\
\text { Ki-67, vimentin) }\end{array}$ \\
\hline
\end{tabular}


fibroma occurring in the palate experience no esthetic or pronunciation disorders at a stage where the mass is small, and so tend to remain untreated [10] [11] [12].

In conventional reports, none showed results of immunological examination for resected fibroma over $30 \mathrm{~mm}$. For our case, distinguishing solitary fibrous tumor from neurofibroma was considered necessary, as both tumors contain fibrous tissue and occur in the palate. Immunohistological examinations for S100, CD34, Bcl-2, and Ki-67 were conducted and ruled out tumor containing nervous system tissue, because subepithelial spindle-shaped cells are S100 protein-negative. CD34-, Bcl-2-, and Ki-67-negative, vimentin-positive, solitary fibrous tumor was also ruled out.

Considering the onset of this case, internal and external factors may have been involved. One internal factor is stimulation of the oral mucosa by endotoxin or proteolytic enzymes from oral bacteria. Endotoxin derived from Porphyromonas gingivalis has been reported to induce interleukin (IL) $1-1 \beta$ in fibroblasts and causes cell proliferation [13]. In addition, abnormalities of specific genes have not been reported in the onset of fibroma, but as NF-1 has been identified as the causative gene in neurofibromatosis type I, the genetic predisposition of individuals may be one cause of onset. As an external factor, the patient had a tongue habit in which he stimulated the palate mucosa with the tongue. Other factors also include stimulation by food contacting the palatal mucosa. Hirakami [14] and Shimizu [15] showed that physical stimulation induces activation of intracellular signaling including MAP kinase and activation of calcium ion channels in the cell membrane. As a result, physical stimulation is reportedly involved in the proliferation of fibroblasts and maturation of extracellular collagen. Furthermore, since the patient's toothbrush came into contact with tumor of the right palate when cleaning the oral cavity about 10 years earlier, this was also considered a potential external factor. This case involved a lesion in the palate with relatively little mechanical irritation and clarifying the cause of occurrence was difficult, but multiple internal and external factors overlap and formation of a tumor in the palatal mucous membrane takes a long time (Figure 7).

\section{$\underline{\text { Internal factor }}$}

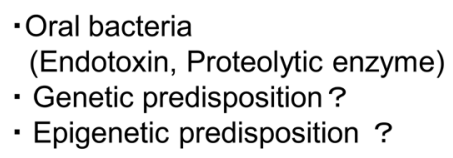

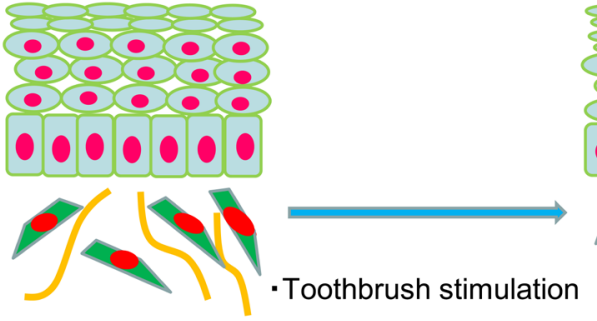

- Intracellular signaling by
MAP kinase
- Activation via Ca ion channel
(Hirakami 2002, Shimizu 1999)

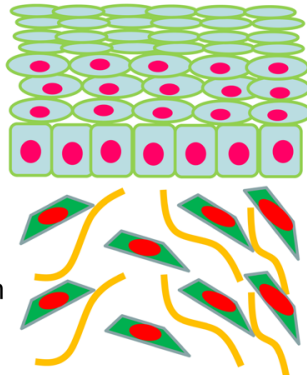

Growth of fibroblast, Maturity of collagen

Figure 7. Consideration of causes in this case. We examined the relationship between internal and external factors, and changes over time in terms of the cause of this case. 
One year after surgery, the oral cavity is covered with mucosa, no recurrence was been identified and the course of the patient has been good.

\section{Conclusion}

Following a long course of more than 30 years, we encountered a case of huge fibroma occurring in the palate, and discussed with reference to immunohistochemical studies and the literature.

\section{Consent}

Written informed consent was obtained from the patient for publication of this case report and accompanying images. A copy of the written consent is available for review by the Editor-in-Chief of this journal on request.

\section{Acknowledgements}

No grants were received in relation to this paper.

\section{Conflicts of Interest}

The authors declare that they have no competing interests.

\section{References}

[1] Kai, S. and Tadayoshi, K. (1967) General Review of Pathology. 2nd Edition, IGAKU-SHOIN Ltd., Tokyo, 774. (In Japanese)

[2] Tamaki, I. (1984) Pathology. 2nd Edition, IGAKU-SHOIN Ltd., Tokyo, 294-300. (In Japanese)

[3] Barker, D.S. and Lucas, R.B. (1967) Localized Fibrous Overgrowths of the Oral Mucosa. British Journal of Oral Surgery, 5, 86-92. https://doi.org/10.1016/S0007-117X(67)80031-3

[4] Gorlin, R.J. and Goldman, H.H. (1970) Thoma's Oral Pathology. 6th Edition, CV Mosby Co, St Louis, 869-871.

[5] Bhasker, S.N. (1977) Synopsis of Oral Disease. 2nd Edition, Mosby Co, St Louis, 458.

[6] Goro, I. and Tasatoyo, A. (1975) Oral Pathology. II, Nagasueshoten, Kyoto, 963. (In Japanese)

[7] Yoshie, Y., Yoshiko, M. and Yoshihisa, W. (2008) Immunohistochemical Study on Characterization of Spindle Cells of Irritation Fibroma. Kanagawa Dental, 43, 20-30. (In Japanese)

[8] Bernier, J.L. (1959) The Management of Oral Disease. 2nd Edition, Mosby Co, St Louis, 415.

[9] Shafer, W.G. and Hine, M.K. (1974) A Textbook of Oral Pathology. 3rd Edition, W.B. Saunders Co, Philadelphia, 127.

[10] Kangi, U. and Kensuke, A. (1968) A Case of Fibroma in the Midline of the Palate. Japanese Journal of Oral and Maxillofacial Surgery, 17, 339. (In Japanese)

[11] Toshihiko, S. and Tomio, T. (1968) A Case of a Huge Fibroma on the Palate. Journal of Oral and Maxillofacial Surgery, 17, 339. 
[12] Tohru, K., Genzaburo, M., Kazuhiko, S., Kiyohide, F., Shilo, K. and Takatoshi, O. (1980) Large Fibroma of the Palate: Report of a Case. Japanese Journal of Oral and Maxillofacial Surgery, 26, 1115. (In Japanese)

[13] Wang, P.L. and Ohura, K. (1999) Effects of LPS and Protease from Porphorro monas gingivalis on Cultured Human Gingival Fibroblasts. Journal of Hard Tissue Biology, 8, 9-14.

[14] Fukumi, H. and Yoshio, K. (2002) Formation of HA Mediated Three-dimensional Structures by Mouse Fibroblasts due to Physical Stimulation. The Japanese Journal of Rehabilitation Medicine, 39, 229-235. https://doi.org/10.2490/jjrm1963.39.229

[15] Shimizu, T., Kato, T., et al. (1999) Coordinated Regulation of Radioadaptive Response by Protein Kinase C and p38 Mitogen-Activated Protein Kinase. Experimental Cell Research, 251, 424-432. https://doi.org/10.1006/excr.1999.4582 